\title{
O PACTO NACIONAL PELA ALFABETIZAÇÃO NA IDADE CERTA (PNAIC) E SUAS AÇÕES: O MONITORAMENTO COMO DESAFIO
}

\section{THE NATIONAL PACT FOR LITERACY IN THE RIGHT AGE (PNAIC) AND ITS ACTIONS: THE CHALLENGE OF MONITORING}

\author{
Amélia Escotto do Amaral Ribeiro ${ }^{1}$ \\ Magda Cristina Dias de Lucena ${ }^{2}$ \\ Ana Claudia dos Santos de $\mathrm{Abreu}^{3}$
}

\section{RESUMO}

A alfabetização e seus resultados, no Brasil, historicamente desafia as políticas públicas de formação de professores. Embora as ações desencadeadas por essas políticas e seus respectivos programas sejam marcadas por certo distanciamento entre os propósitos legislativos e as condições reais de implementação, tornam-se cada vez mais necessárias. Dentre as políticas recentes, serve de exemplo o Pacto Nacional pela Alfabetização na Idade Certa (PNAIC), voltado para a formação continuada de alfabetizadores. Nessa perspectiva, neste artigo analisam-se, a partir das determinações do PNAIC, as estratégias de acompanhamento de processos e resultados, especificamente as formas de monitoramento propostas. A análise ratifica como desafios: o uso do princípio da performatividade, os resultados das avaliações externas como critério de acompanhamento das ações e a efetividade desses resultados no contexto do cotidiano escolar.

Palavras-chave: Alfabetização. Pacto nacional pela alfabetização na idade certa. Monitoramento

\begin{abstract}
\footnotetext{
${ }^{1}$ Doutorado em Educação e mestrado em Filosofia e Educação pela PUC/Rio.

${ }^{2}$ Mestrado em Educação pela UERJ/FEBF.

${ }^{3}$ Mestrado em Educação pela UERJ/FEBF.
}

In Brazil, literacy and its results has historically challenged public policies for teachers' education. The undertaken actions of these policies and their respective programs are becoming increasingly necessary, in spite of being marked by a certain distance between legislative objectives and their actual implementation conditions. Among recent policies, the National Pact 
for Literacy in the Right Age (PNAIC), aimed at the continuing education of literacy teachers, is an example. By considering PNAIC determinations, this article analyses the strategies of literacy processes and their results assessment, especially, their proposed ways of monitoring. The analysis ratifies the following challenges: use of principles of performativity, the external assessment results as a criterion of monitoring these actions and the effectiveness of these results in the context of everyday school life.

Keywords: Literacy. National pact for literacy in the right age. Monitoring.

\section{INTRODUÇÃO}

A alfabetização escolar, aqui se referindo especialmente ao processo de ensino e aprendizagem da leitura e escrita em língua materna, nos anos iniciais da escolarização assume um caráter complexo e multifacetado. Por se caracterizar como dever do Estado e direito do cidadão, para que se efetive, pressupõe ações políticas que promovam e, ao mesmo tempo, garantam um conjunto de condições para que a aprendizagem ocorra da forma mais significativa possível.

A Resolução CNE/CBE n 7, de 2010, em seu artigo 30 assim se refere aos três anos iniciais “[...] devem assegurar: I - a alfabetização e o letramento; II - o desenvolvimento das diversas formas de expressão [...]; III - a continuidade da aprendizagem, tendo em conta a complexidade do processo de alfabetização [...]" (BRASIL, 2010, p. 8).

Verifica-se pelo excerto a ênfase à alfabetização e ao letramento enquanto focos do trabalho nos anos iniciais da escolarização, reconhecendo-os como decisivos para a continuidade das aprendizagens e, portanto, como fatores relevantes para a permanência dos alunos na escola. Face a amplitude e complexidade da tarefa atribuída a essa fase inicial, ganham destaque as questões relacionadas à dimensão da organização pedagógica, sobretudo, em termos da busca por procedimentos que tornem a aprendizagem mais efetiva. Em outras palavras, admite-se uma relação estreita entre a habilidade didático-pedagógica do professor para respeitar as diferentes e promover o acesso ao conhecimento, especialmente, sobre a língua portuguesa, sua estrutura e os seus usos sociais. Nessa mesma direção, já em 2008, o Parecer $\mathrm{CNE} / \mathrm{CEB} \mathrm{n}^{\circ} 4$, indicava que "[...] a alfabetização dar-se-á nos três anos iniciais do Ensino Fundamental [...] (BRASIL, 2008, p.2).

Essa questão que envolve a alfabetização não é nova. Ao abordar a alfabetização e o analfabetismo no contexto brasileiro, Ferraro (2014) demarca temporalmente suas reflexões em 
três períodos. O primeiro, de 1878 até 1881 , diz respeito à “introdução do voto direto no império (...) quando o analfabetismo é erigido em problema nacional e o analfabeto é estigmatizado e excluído do direto de voto". Nesse período, a questão da estigmatização do analfabeto referese ao sentido das articulações do saber ler e escrever e o exercício do voto.

É possível perceber que já nessa época o termo analfabetismo e analfabeto estava associado a aspectos negativos, como [...] condição de ignorância, de cegueira, de pauperismo, de falta de inteligência e discernimento intelectual e, por isso tudo de incapacidade política [...] o analfabetismo ganha também a conotação de marginalidade e periculosidade" (FERRANO; LEÃO apud FERRARO, 2014 p. 71).

No que diz respeito ao segundo período, de 1950 até 1980, este é "marcado (...) pela repressão contra os movimentos populares e pela imposição do Movimento Brasileiro de Alfabetização - MOBRAL, no lugar de experiência populares de alfabetização inspiradas, principalmente, por Paulo Freire" (FERRARO, 2014, p.66). Esse período fica conhecido como o período da efervescência das discussões que opunham a proposta de Paulo Freire, articulada com os movimentos sociais, e a proposta oficial - o MOBRAL. Nesse contexto, a intenção era camuflar a dimensão política da alfabetização, reduzindo-a aos seus aspectos puramente técnicos.

O terceiro período se inicia a partir da Constituição de 1988, com "a afirmação da educação fundamental como direito público e subjetivo e [...] tem o ano de 2016 como horizonte e prazo limite para extensão desse direito à toda Educação Básica, [...] (FERRARO, 2014, p.66). Ainda segundo o autor, tomando-se como base o Artigo 208 da Constituição de 1988, não há somente

[...] a afirmação declaratória e programática do direito universal e do dever do Estado, no que concerne no ensino fundamental, mas também a definição de que esse é um direito público subjetivo e, como tal, irrenunciável e exigível, mediante a responsabilização da autoridade competente no caso de não oferta ou de oferta irregular do bem chamado ‘Educação' (FERRARO, 2014, p. 78.).

A partir do excerto percebe-se, em comparação aos outros dois períodos, a grande novidade para a Educação: o seu reconhecimento como um direito irrenunciável e exigível.

Contudo, a alfabetização e suas questões ainda permanecem no cenário da educação brasileira, especialmente no que diz respeito aos sentidos da alfabetização para os alunos oriundos das camadas populares. As articulações entre o sentido da alfabetização e as ações desencadeadas pelas políticas públicas ainda se constituem um desafio. 
Chamam a atenção os dados do Indicador do Alfabetismo Funcional (INAF) 2011-2012. Segundo pesquisa produzida pelo Instituto Paulo Montenegro e a organização não governamental Ação Educativa, apenas $26 \%$ da população podem ser consideradas plenamente alfabetizadas. Os chamados analfabetos funcionais representam $27 \%$ e a maior parte $(47 \%)$ da população apresenta um nível de alfabetização básico. Esses dados sugerem a importância de estudos e ações com vistas à melhoria da qualidade do processo de ensino e aprendizagem da leitura e escrita no âmbito escolar, tanto do ponto de vista da produção de conhecimento sobre esse campo quanto do aperfeiçoamento das políticas públicas, sobretudo daquelas voltadas para a formação continuada de professores.

No âmbito das políticas públicas, o Ministério da Educação vem tentando desenvolver um conjunto de ações através da proposição de programas de formação continuada para professores alfabetizadores, na tentativa de superar a distorção idade/série. Os programas desenvolvidos têm como foco a reconfiguração dos indicadores de desempenho escolar, especialmente em leitura e escrita. Dentre esses programas o Pacto Nacional pela Alfabetização na Idade Certa (PNAIC) se apresenta como resultado de estudos "no sentido de favorecer a construção de políticas públicas que venham de fato reverter os indicadores de desempenho dos alunos que hoje estão nas escolas de todo país, e um dos caminhos apontados é a formação continuada de professores" (BRASIL, 2012, p. 9).

A questão da alfabetização, em termos de efetividade e resultados, vem sendo incorporada de forma cada vez mais explícita nos planos nacionais de educação mais recentes (2001- 2010 e 2014 - 2024).

O Plano Nacional de Educação ( 2014 - 2024), por exemplo, em sua meta 5 faz alusão direta ao PNAIC, quando ratifica a necessidade de "alfabetizar todas as crianças, no máximo, até o final do 3ํo (terceiro) ano do ensino fundamental” (BRASIL, 2014 p.10).

Nesse contexto, considerando-se o distanciamento entre os propósitos legislativos e suas intenções das condições reais de execução e operacionalização, questionam-se aqui, em se tratando do PNAIC, as estratégias de acompanhamento de processos e resultados indicados. Acredita-se que as questões das estratégias de acompanhamento da efetividade das ações do PNAIC merecem um olhar mais cuidadoso. Dada a abrangência do programa e de suas ações, elegem-se as estratégias de monitoramento como foco de análise. Tais estratégias chamam a atenção na medida em que não consideram os sujeitos reais que compõem as redes do programa. Ao se utilizarem, predominantemente, do princípio da performatividade e de avaliações 
externas, mesmo quando envolvem de alguma forma os diferentes atores, não os contemplam em suas angústias e demandas pessoais e contextuais.

Portanto, pode-se dizer que o processo de monitoramento é um dos desafios a ser enfrentado na implementação e efetivação do Pacto Nacional pela Alfabetização na Idade Certa (PNAIC).

\section{Aproximações entre o PNE e o PNAIC: a alfabetização como foco}

Enquanto política pública, o Plano Nacional de Educação (PNE) 2001-2010 já prevê a formação continuada de professores alfabetizadores em serviço. Entende-se, aqui, políticas públicas como "tudo o que um governo faz e deixa de fazer, com todos os impactos de suas ações e de suas omissões" e política pública educacional como as decisões do governo que têm incidência no ambiente escolar enquanto local de ensino-aprendizagem (AZEVEDO, 2003, p. $38)$.

A demanda por formação de professores alfabetizadores é uma tentativa de desencadear ações, as mais colaborativas possíveis, envolvendo o Governo Federal, Estados, Municípios e Universidades na busca de soluções mais efetivas para o problema da alfabetização (SANTOS, 2012). Nesse contexto, destaca-se que o envolvimento de vários segmentos na coordenação, financiamento e manutenção de programas de formação de professores alfabetizadores tem no PNAIC sua ação mais recente.

O programa funciona com um formato de curso presencial para os professores alfabetizadores, pautado em estudos teóricos e atividades práticas. A dinâmica metodológica proposta pelo PNAIC prevê a articulação entre o que é discutido nos encontros de formação, as indicações para a prática e a prática do professor propriamente dita. Sobre essa articulação é possível dizer que nem sempre ela ocorre de maneira efetiva. Em outras palavras, de fato não se tem como avaliar se o discurso do professor sobre a sua prática revela a própria prática. Em

alguns casos e contextos, em situações mais informais, professores comentam "o que me é apresentado aqui não pode ser aplicado na minha realidade; sobre o que faço, digo o que os formadores querem ouvir".

Para uma ampliação do entendimento a respeito das proposições do PNAIC é fundamental considerar as articulações desse programa com o PNE. O manual do PNAIC aponta que "a Meta 5 do Projeto de Lei que trata sobre o Plano Nacional de Educação também reforça este aspecto ao determinar a necessidade de alfabetizar todas as crianças até, no máximo, os oito anos de idade" (BRASIL, 2014, p.11). 
No contexto do que se apresenta neste texto, o Plano Nacional de Educação pode ser entendido como um arranjo potencializador para que as instituições criem suas metas e seus Projetos Políticos Pedagógicos de gestão, bem como organizem táticas de investimento que influenciem positivamente a vida da população.

A discussão sobre a necessidade ou não de um Plano Nacional de Educação brasileiro não é algo novo ou atual. Pode-se dizer que desde o surgimento da República, tem-se discutido sobre a efetividade de um documento formulado pela União com papel de lei para nortear os planos estaduais e municipais de educação. Saviani (2010) afirma que para um sistema permanecer vivo e não acabar em uma simples estrutura engessada e burocratizada, é necessário manter continuamente a intencionalidade das ações. Para ele, o plano educacional é "o instrumento que visa introduzir racionalidade na prática educativa como condição para superar o espontaneísmo e as improvisações, que são o oposto da educação sistematizada e de sua organização na forma de sistema" (SAVIANI, 2010, p. 389).

Em janeiro de 2001 é aprovado o primeiro PNE do país, com força de lei (Lei $n^{o}$ 10.172/2001), e com uma duração prevista de 10 anos para o cumprimento de suas metas. Os objetivos estabelecidos por esse plano visavam formar sujeitos com mobilidade para viver num mundo em constantes mudanças, e que conseguissem se adequar facilmente aos preceitos globais. Desta forma, o acesso à escola está vinculado ao exercício da cidadania.

Dentre as ações indicadas pelo PNE (2001 -2010), é possível destacar que o documento também prevê avaliações periódicas da implementação do plano, estabelecendo como parâmetros dessa avaliação um monitoramento feito através de avaliações externas e de larga escala. Dentre essas avaliações, a Avaliação Nacional da Alfabetização (ANA) que se volta especialmente para a alfabetização.

Em conformidade com cenário educacional da época, o PNE (2001-2010) traz em seu texto uma ênfase nos aspectos relacionados à promoção do acesso e à garantia da permanência dos alunos nas escolas. Mesmo sendo um ganho em termos da democratização do ensino, a alfabetização e suas questões ainda não eram o foco principal.

Nessa perspectiva, o PNE (2001 - 2010) acabou funcionando como tática de regulamentação do direto da população à educação tendo em vista que em alguns lugares esse direito ainda não era garantido.

Por se tratar de um Plano com duração prevista para dez anos, em 2009 todos os sistemas educacionais iniciaram as discussões para elaboração de uma nova proposta. Muitas críticas foram feitas ao PNE (2001 - 2010). Saviani (2010), por exemplo, destaca a extensão e falta de 
objetividade na formulação das metas e dos objetivos que foram traçados. Acredita que seria necessário “(...) repensar a estrutura do plano concentrando-se nos aspectos fundamentais e, em consequência, enxugando o texto e reduzindo o número de metas, seja pela aglutinação daquelas afins, seja fixando-se nos aspectos mais significativos (SAVIANI, 2010, p. 391).

Em 2014 um novo PNE é aprovado, estabelecendo para o período de 2014-2024 uma organização mais clara dos objetivos. Estabelece um total de 20 metas associadas às 253 estratégias voltadas para a educação básica, educação superior e valorização e remuneração dos profissionais da educação.

O novo PNE se ocupa fundamentalmente das garantias de uma educação de boa qualidade e do direito à aprendizagem, assegurando, em seu texto, o direito do sujeito a aprender especialmente nos anos iniciais da escolarização. Destaca:

[...] as metas são orientadas para enfrentar as barreiras para o acesso e a permanência; as desigualdades educacionais em cada território com foco nas especificidades de sua população; a formação para o trabalho, identificando as potencialidades das dinâmicas locais; e o exercício da cidadania. (BRASIL, 2014, p.9)

O texto do PNE 2014-2024 retoma o desafio das articulações entre a universalização da Alfabetização da Educação Básica com as políticas públicas. Do mesmo modo, indica a ideia da importância da alfabetização/escolarização para a melhoria da condição humana. Pontua, ainda, o acesso e a permanência dos alunos na escola como um fator preponderante para o êxito da proposta.

Há metas que estruturam a ideia de boa qualidade da educação básica, outras que especificam a necessidade de forte investimento na Educação Infantil; outras tratam da redução das desigualdades, viabilização plena à educação básica obrigatória e gratuita, a valorização dos profissionais da educação e de uma maior participação das esferas governamentais na elaboração das metas para o Ensino Superior.

Em relação à alfabetização, o PNE 2014 - 2024 destina uma meta específica para este campo. Como já se assinalou anteriormente, propõe "alfabetizar todas as crianças, no máximo, até o final do $3^{\text {o }}$ (terceiro) ano do ensino fundamental" (BRASIL, 2014, p.10).

As principais estratégias definidas pelo PNE para o cumprimento da Meta 5, voltam-se para a melhoria da formação do professor alfabetizador, sobretudo no que diz respeito aos aspectos didático-pedagógicos. Ressaltam-se:

[...] a estruturação de processos pedagógicos nos anos iniciais do ensino fundamental, [...] e valorização dos professores alfabetizadores e apoio pedagógico específico, [...] o fomento ao desenvolvimento de tecnologias educacionais e de inovação das práticas pedagógicas, bem como a seleção e divulgação de tecnologias que sejam capazes de alfabetizar e de favorecer a 
melhoria do fluxo escolar e a aprendizagem dos alunos. Tudo isso sem que se deixe de assegurar a diversidade de métodos e propostas pedagógicas nos processos de alfabetização. (BRASIL, 2014, p. 26-27).

Na perspectiva do PNE, a formação continuada dos professores implica, ao mesmo tempo, domínio do conhecimento sobre o objetivo a ser ensinado e domínio pedagógico vasto que permita promover a aprendizagem, utilizando-se de estratégias diversificadas. Cabe destacar que os saberes didáticos são considerados vitais para o exercício profissional. Nesse sentido, os conhecimentos específicos e o conhecimento didático-pedagógico constituem o repertório de saberes docentes necessários ao fazer alfabetizador.

O conhecimento da língua é considerado essencial para a prática alfabetizadora, tendo em vista a necessidade do docente entender as especificidades do processo de aquisição e aprendizagem da língua, principalmente no que diz respeito às habilidades de escrita e leitura. Assim, a formação precisa contribuir para que o professor se aproprie de conhecimentos não apenas sobre a língua, mas, principalmente, de conhecimentos que lhe permitam pensar pedagogicamente sobre as aprendizagens implicadas, e necessárias, no aprender a ler e a escrever. E, a partir dessa reflexão que articula teoria e prática, possa fazer escolhas didático pedagógicas mais significativas.

Chama também a atenção, do ponto de vista das estratégias propostas pelo PNE, a relação que se estabelece entre o uso de avaliações externas/de larga escala como estratégia de avaliação e monitoramento do cumprimento da meta. Encontra-se a esse respeito:

[...] a instituição de instrumentos de avaliação nacional periódicos e específicos para aferir a alfabetização das crianças, aplicados a cada ano, bem como estimular os sistemas de ensino e as escolas a criar os respectivos instrumentos de avaliação e monitoramento, implementando medidas pedagógicas para alfabetizar todos os alunos e alunas até o fim do terceiro ano do ensino fundamental. (BRASIL, 2014, p.27).

O plano determina, ainda, que para o cumprimento da Meta 5 sejam considerados

1. O Censo da Educação Básica;

2.as orientações sobre como ter acesso aos programas e projetos para o ensino fundamental; 3. das Resoluções da Câmara de Educação Básica e do Pleno do Conselho Nacional de Educação (CNE) sobre educação infantil;

4. do Pacto pela Alfabetização na Idade Certa (PNAIC). (BRASIL, 2014, p. 27).

Dentre as indicações previstas nessa meta, o PNAIC, como já citado anteriormente, figura como uma política pública de formação continuada em alfabetização com vistas à efetivação da alfabetização até os 8 anos de idade. O programa afirma que o objetivo não é somente alfabetizar, mas garantir a boa qualidade e o direito da aprendizagem de cada criança, respeitando seu tempo e modo de aprender. Como aponta o artigo 5 da Portaria 867, de 4 de julho 2012, que institui o PNAIC, seus objetivos são: 
I - garantir que todos os estudantes dos sistemas públicos de ensino estejam alfabetizados, em Língua Portuguesa e em Matemática, até o final do $3^{\circ}$ ano do ensino fundamental;

II - reduzir a distorção idade-série na Educação Básica;

III - melhorar o Índice de Desenvolvimento da Educação Básica (IDEB);

IV - contribuir para o aperfeiçoamento da formação dos professores alfabetizadores;

V - construir propostas para a definição dos direitos de aprendizagem e desenvolvimento das crianças nos três primeiros anos do ensino fundamental. (BRASIL, 2012, p.22)

Do exposto, pode-se depreender a complexidade e a abrangência que envolve especialmente a operacionalização das ações propostas. Chama a atenção alguns pontos como: a utilização das avaliações de larga escala; as relações entre processos pedagógicos e a garantia dos direitos de aprendizagem; o prazo para a promoção das aprendizagens em alfabetização; a ênfase em língua portuguesa e matemática; a articulação dos anos iniciais com a Educação Infantil; a instrumentalização dos professores no uso das tecnologias, recursos e conhecimentos que tornem a aprendizagem mais significativa e os resultados mais satisfatórios; o conceito de idade certa ou da temporalidade de 3 anos para que o processo de alfabetização se consolide; redução da distorção idade-série.

Diante da abrangência e volume das ações pretendidas, pode-se inferir como desafio para a sua implantação, a questão do acompanhamento/monitoramento. Sobretudo, se forem consideradas as questões de contextos, práticas e atores nelas implicados.

\section{O PNAIC e seus desafios de implementação e acompanhamento}

Se consideradas as ações desenvolvidas pelo PNAIC, é possível observar que o programa, ao buscar estratégias para assegurar a alfabetização de todas as crianças brasileiras que ainda não adquiriram o sistema de escrita alfabética, articula os direitos de aprendizagem à questões didático-pedagógicas. Essas se justificam na medida em que pretendem contribuir

[...] para o debate acerca dos direitos de aprendizagem das crianças do ciclo de alfabetização; para os processos de avaliação e acompanhamento da aprendizagem das crianças; para o planejamento e avaliação das situações didáticas; para o conhecimento e uso dos materiais distribuídos pelo Ministério da Educação, voltados para a melhoria da qualidade do ensino no ciclo de alfabetização. (BRASIL,2014, p.1)

Acredita-se, assim, que a qualificação dos professores, e a consequente melhoria das suas práticas, resulta em melhoria da qualidade da aprendizagem dos alunos. Na verdade, a melhoria da formação do professor passa a ser uma estratégia para que os direitos de aprendizagem no ciclo de alfabetização sejam garantidos. Assim, a formação continuada 
proposta pelo PNAIC é entendida não como uma ação que pretenda apenas suprir eventuais lacunas de formação, mas como direito profissional a ser exercido continuamente em diferentes momentos e em diferentes formatos (CARVALHO e FRADE, 2014).

Vale ressaltar que o investimento principal do PNAIC é a formação continuada. O próprio documento entende que a formação do professor não se encerra na conclusão do seu curso de graduação, mas se realiza continuamente na sala de aula, onde dúvidas e conflitos o desafiam cotidianamente. Nesse sentido, uma das possibilidades de superação de dificuldades é a oportunidade de discutir com outros profissionais da educação, e com os pares. Isso pode favorecer a troca de experiências e propiciar reflexões mais aprofundadas sobre a própria prática.

A ideia da constituição profissional na e através da prática, em constante diálogo com os pares, se alinha às discussões contemporâneas sobre a formação inicial e continuada de professores. Tais discussões entendem a formação continuada como processo de reflexão e socialização da prática educativa, como mecanismo de emancipação do sujeito, sendo a escola como lócus privilegiado dessa formação (NOVOA, 1992). Ressaltam o processo de desenvolvimento profissional no sentido de evolução, continuidade e interconexão entre a formação inicial e a continuada de forma a superar os limites didáticos e as práticas individualistas.

Desta forma, a formação continuada de professores pode ser compreendida como "um processo permanente de aperfeiçoamento dos saberes necessários à atividade profissional, realizado após a formação inicial, com o objetivo de assegurar um ensino de melhor qualidade aos educandos". (CHIMENTÃO,2009, p.3). Portanto, as políticas de formação continuada deveriam ter como foco o desenvolvimento de conhecimentos e habilidades cognitivas e comportamentais que permitissem ao professor utilizar conhecimentos científicos e tecnológicos de modo articulado para resolver problemas de prática pedagógica, social e produtiva (SANTANA, 2011). O processo de formação continuada, quando assim compreendido, implica a articulação entre: a escola, como locus privilegiado de formação; a valorização do saber docente; e o ciclo de vida dos professores. (CANDAU, 1997).

Embora algumas vezes criticada por suas dimensões político-ideológicas, a formação continuada, se constitui como espaço de formação docente indispensável à atualização e promoção da boa qualidade da atuação docente.

Entendida como um espaço em que questões e desafios mais específicos são contemplados, a formação continuada pode representar a oportunidade de troca de experiências, 
de valorização da capacidade e experiência dos professores, sobretudo de contato com contribuições da literatura pedagógica mais recente. Chama atenção o fato de que no contexto brasileiro, a formação continuada de professores para os anos iniciais da escolarização tem sido objeto de vários projetos e programas, como por exemplo o Programa de Formação de Professores Alfabetizadores (PROFA), Pró-Letramento e, o mais recente, o Pacto Nacional pela Alfabetização na Idade Certa (PNAIC). O conjunto desses projetos e programas atende aos princípios de "atualização e adaptação às condições de trabalho em constante mudança" (GROXKO e PAIVA, 2008, pág. 3464), embora boa parte deles seja proposta por instâncias externas à escola, como o Ministério da Educação e as Secretarias Estaduais e Municipais de Educação.

Observa-se que, de uma forma ou de outra, cada um deles se ocupa em contemplar a dimensão pedagógica da atuação do professor, voltando-se para questões mais especificas, em especial àquelas relacionadas ao campo da linguagem. Em outras palavras, à alfabetização em língua materna e matemática (SOUZA, 2008).

Nessa perspectiva, o PNAIC propõe estratégias e instrumentos para garantir que os envolvidos nessa formação utilizem e disponham de recursos para aprimorar sua formação e prática. A formação oferecida precisa garantir, ainda, o aprofundamento dos conhecimentos sobre alfabetização, interdisciplinaridade e inclusão como princípio fundamental do processo educativo.

O documento introdutório do PNAIC aponta que "a formação de professores está intimamente ligada às questões do conhecimento, do currículo, das mudanças culturais e das novas tecnologias " (BRASIL, 2012, p. 27). Esse documento destaca, ainda, na perspectiva do desenvolvimento de uma cultura de formação continuada, que para que tal cultura seja implantada tornam-se necessários compromissos a serem assumidos em âmbito institucional e individual. Assinala:

O compromisso institucional (do Governo Federal e das secretarias de educação) reside principalmente na necessidade de promover espaços, situações e materiais adequados aos momentos de trabalho e reflexão, compreendendo que a formação continuada não é um treinamento no qual se ensinam técnicas gerais a serem reproduzidas. Se concebemos os professores como sujeitos inventivos e produtivos, sabemos que eles não serão repetidores em suas salas de aula daquilo que lhes foi aplicado na formação para orientar a sua nova prática. Sabemos sim que, a partir de diferentes estratégias formativas, eles serão estimulados a pensar sobre novas possibilidades de trabalho que poderão incrementar e melhorar o seu fazer pedagógico cotidiano. (BRASIL, 2012, p. 27). 
No que se refere às questões relacionadas ao conhecimento, o PNAIC aponta para a necessidade do professor entender a alfabetização como um processo que integra a aprendizagem do Sistema de Escrita Alfabética e apropriar-se dos conhecimentos e habilidades específicas do ensino desse sistema. Além de considerar a experiência como fonte de saberes, chama a tenção que a formação continuada proposta pelo PNAIC se volta para o domínio dos conhecimentos gerais sobre o ensinar e o aprender, e os saberes específicos da aquisição da leitura e escrita.

Para contribuir com as práticas em sala de aula, o caderno de apresentação do PNAIC destaca também que é possível contribuir para a alfabetização plena das crianças se o professor introduzir às suas práticas, atividades que envolvam novas tecnologias. Dentre as estratégias formativas do programa, as tecnologias digitais são estimuladas, especialmente, no uso de computadores e internet para o desenvolvimento de práticas pedagógicas inovadoras. Tais práticas se justificam pela necessidade de considerar e atender a diversidade de alunos (campo, indígenas, quilombolas, populações itinerantes) na perspectiva da educação inclusiva. Nesse contexto, espera-se que a formação do professor alfabetizador fortaleça o respeito à diversidade e a garantia dos direitos da educação. Assim, a escola poderá favorecer a construção de um espaço de promoção e valorização das diversidades que compõe a sociedade brasileira. Contribuindo, assim, para a promoção de formas mais efetivas de inserção dos sujeitos na sociedade, pautadas na vivência e no exercício da cidadania. É fundamental que esse exercício da cidadania e dos valores democráticos sejam promovidos na e pela escola, nas diferentes experiências de aprendizagem que oferece aos alunos.

Entendida como um dos possíveis instrumentos de inserção do aluno na sociedade, a perspectiva inclusiva da educação propõe que o docente possa refletir sobre as suas práticas e adequá-las às necessidades do seu público de modo a garantir que os diferentes sujeitos que compõem esse público, os direitos de aprendizagem. Em se tratando da alfabetização, especialmente àqueles relacionados à apropriação e uso do Sistema de Escrita Alfabética. Sendo o Sistema de Escrita Alfabética considerado pelo PNAIC como um direito de aprendizagem, torna-se imprescindível a reformulação do currículo para a proposição de práticas inclusivas.

Nesse contexto, é possível destacar que a ideia de currículo também é permeada pela indicação da necessidade de que as garantias dos direitos de aprendizagem sejam tomadas como um compromisso de toda a sociedade e, especialmente, das unidades escolares. Embora se reconheça certo distanciamento entre as proposições das políticas públicas e o que, de fato, é construído em diferentes contextos e a partir de múltiplas interpretações, o currículo “(...) não 
pode ser entendido como decisão de cada um. Precisa ser, na verdade, fruto de construções coletivas que tenham como norte princípios partilhados". (BRASIL, 2012, p.6).

Nesse cenário em que se prevê a formação continuada de professores alfabetizadores como estratégia para a garantida dos direitos de aprendizagem, ratificado pelo Plano Nacional de Educação, o PNAIC vem ganhando força como uma política de formação continuada que busca contribuir para a superação dos indicadores de alfabetização, considerados insuficientes até então. Embora ganhe força, um dos pontos ainda pouco compreendido, e muito questionado, é a questão das estratégias de monitoramento de suas ações.

\section{III- Análise das estratégias de acompanhamento e efetividade das ações do PNAIC}

Tomando-se como referência as estratégias adotadas pelo PNAIC para a efetivação do programa, elegeu-se como foco de reflexão, neste texto, o monitoramento como ação da gestão pública federal, para garantir a implementação e o acompanhamento das diferentes etapas. A análise incide sobre o que se explicita a esse respeito no Eixo 4- Gestão, controle social e mobilização da sociedade e da comunidade escolar. Cabe acrescentar que esse eixo prevê quatro instâncias de gerenciamento:

[...] um Comitê Gestor Nacional; uma coordenação institucional em cada estado, composta por diversas entidades, com atribuições estratégicas e de mobilização em torno dos objetivos do Pacto; Coordenação Estadual, responsável pela implementação e monitoramento das ações em sua rede e pelo apoio à implementação nos municípios; e Coordenação Municipal, responsável pela implementação e monitoramento das ações na sua rede de ensino (BRASIL, 2012, p.14).

Encontra-se no Eixo 4 do PNAIC a proposição de uma "ferramenta" para o sistema de monitoramento. Aponta-se "[...] a importância do sistema de monitoramento disponibilizado pelo MEC, o SISPACTO, destinado a apoiar as redes e a assegurar a implementação das diferentes etapas do Pacto". (MEC,2012, p.14). Implica, portanto, uma concepção de gestão, controle e acompanhamento que tem no monitoramento um sistema que permite acompanhar a efetividade das ações do PNAIC. Ações essas desenvolvidas pelas diferentes instâncias de atuação e operacionalização, da universidade ao professor alfabetizador.

As análises que têm sido feitas sobre o gerenciamento das políticas públicas (BALL, 2005 e ESQUINSANI, 2010) apontam como elemento de crítica o uso de modelos marcados especialmente pelo princípio da performatividade, importado "dos modelos empresariais de gerenciamento". Essa lógica, inspirada nos interesses do mercado, se consolidam a partir dos critérios de eficiência e eficácia. (SANTOS, 2004). 
Compreende-se, então, por princípio da performatividade a construção e publicação de informações e de indicadores, como mecanismos para estimular, julgar e comparar profissionais em termos de resultados (BALL, 2005). A partir dessa lógica:

[...] a vinculação entre performatividade e aferições de qualquer natureza no campo educacional (desde testes de larga escala até as avaliações rotineiras que acontecem no interior dos sistemas e unidades educativas) é até simplista, pois que na performatividade [...] os desempenhos (de sujeitos individuais ou organizações) servem como medidas de produtividade e rendimento, ou mostras de qualidade ou ainda momentos de promoção ou inspeção. Significam, englobam e representam a qualidade, a validade ou valor de um indivíduo ou organização dentro de um determinado âmbito de julgamento/ avaliação. (BALL, 2002, p. 4).

O princípio da performatividade assume, pois, a tendência de nomear, diferenciar e classificar, em outras palavras, indica uma cultura de rankiamento. Essa forma de classificação tem sido feita por avaliações externas, que divulgam os resultados do melhor para o pior. Embora se diga que as avaliações externas têm como finalidade última dar visibilidade para os resultados das políticas públicas, esses resultados nem sempre são apropriados pelos professores e seus contextos na revisão prática e projetos educacionais escolares.

Esses modelos, portanto, não seriam os mais adequados para o acompanhamento de políticas públicas em educação. No entanto, são utilizados para monitorar as ações desencadeadas pelo PNAIC. Sobre a importância do uso de avaliação externa, no Manual do PNAIC encontra-se:

Ela servirá para verificar se as crianças estão alfabetizadas e com condições de seguir seu fluxo escolar. Os dados serão disponibilizados logo no início do ano seguinte para elaboração de estratégias de prosseguimento do trabalho escolar. [...] Uma avaliação externa universal é importante, pois não afere somente os resultados obtidos pelos estudantes, mas sim todo esforço empenhado pelos sistemas e redes de ensino para o cumprimento da meta (BRASIL, p. 35).

Como contraponto, a respeito da busca por outros parâmetros de avaliação, vale destacar:

As avaliações de alunos não podem avaliar o Pacto, principalmente porque uma ação de formação não é um botão que você aperta para modificar uma realidade imediatamente. Uma avaliação tem que cumprir sua função de monitoramento, de saber o que as crianças brasileiras estão sabendo. Eu acho que temos, sim, que avaliar o Pacto, mas com outros mecanismos. Como o Pacto é uma mobilização social, temos que avaliar como os municípios passaram a conceber a organização da alfabetização, a formação de professores, como é que modificou a relação deles com os acervos que chegam, como se modificou a criação de bibliotecas e salas de leitura (FRADE, 2014, p. 14).

Cabe assinalar que o programa de monitoramento do PNAIC foi criado pelo Ministério da Educação, em forma de site, http://pacto.mec.gov.br/gestao, no qual os alunos e orientadores 
de estudo tem acesso e utilizam esse espaço como forma de avaliação do Programa. Através dessa plataforma,

[...] todos os envolvidos nesta iniciativa poderão registrar e acessar informações sobre o andamento dos cursos nos estados, municípios e escolas, incluindo registros de presença, realização das atividades planejadas, informações sobre o progresso dos alunos. [...] Além deste sistema, outras ferramentas estarão disponíveis para acompanhar o Pacto, como portais de informação, encontros sistemáticos, publicações e outros recursos dedicados ao tema. (MEC,2012, p. 37).

Em se tratando especificamente do monitoramento das ações desenvolvidas e sugeridas pelo PNAIC, conforme já sinalizado, o SISPACTO foi implantado pelo MEC em forma de site. O SIMEC é um portal operacional e de gestão do MEC, que trata do orçamento e das propostas on-line, preparação para convênios, e para receber assistência técnica e financeira do Governo Federal na área da educação. Pelo SIMEC, cada ente federado pode fazer o diagnóstico de sua situação e propor ações para superar as dificuldades ou para melhorar o desempenho de sua rede.

Do ponto de vista do funcionamento do portal, para ter acesso ao sistema basta acessar a página da internet do SIMEC. O sistema é composto por módulos desenhados com a intenção de facilitar a sua utilização pelo usuário. Os módulos se dividem de acordo com os programas de políticas públicas em vigor, criadas pelo governo federal.

O usuário se cadastra no sistema já no programa de formação que está fazendo. Por exemplo, os sujeitos envolvidos com a formação oferecida pelo PNAIC acessam somente o módulo do PNAIC no SIMEC. Vale destacar, também, que cada sujeito envolvido tem acesso a uma plataforma diferente com tarefas diferentes. Todos precisam dar conta das suas tarefas de acordo com os prazos estabelecidos pelo próprio MEC. A plataforma é "alimentada" através do resultado dos relatos dos professores alfabetizadores e seus orientadores de estudo e dos resultados das avaliações externas aplicadas nas escolas dos professores participantes.

Ao orientador de estudos cabe avaliar seu coordenador e seus alunos, e também se auto avaliar. Os professores avaliam seus orientadores, se auto avaliam, e ainda precisam enviar atividades que são solicitadas pelo MEC. Através dessas atividades se acompanha o desenvolvimento do professor em sua prática após os momentos de formação. O objetivo das avaliações é possibilitar que docentes e gestores acompanhem o desenvolvimento da aprendizagem dos alunos.

O MEC avalia todo o processo por meio de avaliações externas. No caso do PNAIC, o acompanhamento e monitoramento das etapas são feitos pela Avaliação Nacional da 
Alfabetização (ANA). Os resultados dessa avaliação são disponibilizados no SIMEC para que o orientador de estudos e os professores saibam como estão suas escolas e secretarias.

Em meio a esse emaranhado de dados, resultados e informações, uma questão se coloca. Esses resultados, por serem avaliados por mecanismos externos, nem sempre possibilitam o envolvimento dos professores e orientadores de estudos que necessariamente são alvo do acompanhamento do programa.

O maior desafio que se depreende da análise do funcionamento do programa está, entre outras coisas, no fato do acompanhamento ser feito predominantemente por meio virtual. Embora se pretenda o cruzamento dos dados, não se pode ter a garantia de que as respostas dadas pelos envolvidos reflitam de fato suas concepções e práticas. Outro ponto diz respeito ao fato de que ao utilizar-se das avaliações externas e seus resultados como indicador de efetividade, o monitoramento deixa de contemplar questões dos professores e seus contextos de ação.

Nesse sentido, fica evidente o distanciamento entre as políticas públicas, seus instrumentos de monitoramento, e seus critérios de avaliação e os contextos reais nos quais essas políticas são operacionalizadas. Contextos esses formados por sujeitos concretos, que vivem no dia das escolas e das salas de aula os dilemas pessoais, profissionais e sociais inerentes a uma prática que tem como fim teleológico a melhoria da condição humana, promovida a partir do acesso ao conhecimento...ao mundo e seus múltiplos letramentos.

\section{CONSIDERAÇÕES FINAIS}

Pelo exposto, reafirma-se que o mecanismo adotado pelo PNAIC para o monitoramento das ações realizadas pelos sujeitos que participam dessa formação está aliado a uma lógica gerencial, onde o Estado tem assumido uma função reguladora da educação.

Foi possível perceber evidências explicitas de que esse mecanismo de monitoramento se pauta em princípios de performatividade. Esses princípios nem sempre são adequados a contextos educacionais, visto que importados de modelos empresariais, aparecem como um método de regulamentação que emprega julgamentos, comparações e demonstrações como meios de controle, atrito e mudança.

Desta forma, a relação da lógica da performatividade com o sistema de monitoramento das ações do PNAIC está justamente no fato de que as ações dos sujeitos avaliados no programa 
são tomadas como referência para os demais, como parâmetro para uma prática considerada eficiente e eficaz para a melhoria do desempenho dos alunos.

Observa-se, ainda, uma imprecisão acerca dessa relação. Os dados disponibilizados por enquanto, ainda são dados universais. O desafio maior, evidenciado aqui, é a captura do real. O professor, ao preencher as informações solicitadas na plataforma, pode interpretar e responder o que lhe é solicitado utilizando ora conteúdos discursivos alinhados ao que dele se espera, sem nenhuma relação com a prática, ora privilegiando exclusivamente a prática ou o que pensa sobre ela. Também, em alguns casos, o coordenador (da formação) não participa dessa formação. Ratifica-se, então, a necessidade de outros instrumentos de monitoramento e acompanhamento que pudessem ampliar a participação dos múltiplos atores que compõem os diferentes níveis de operacionalização do Programa.

Sendo assim, é essencial um processo sistemático de revisão das estratégias de execução, monitoramento e controle das políticas públicas, em especial do PNAIC, no sentido de verificar se, de fato, estão desempenhando a função social para a qual foram criados. Para isso, duas questões são cruciais: a ideia de monitoramento precisa ser amadurecida e revista nas suas matrizes teórico-metodológicas, e uma análise mais cuidadosa da função social a ser cumprida pelas estratégias de monitoramento e execução.

Nesse sentido, sugere-se que tanto o tema do monitoramento quanto da função social das estratégias, sejam amplamente discutidos e investigados, envolvendo todas as instâncias implicadas no PNAIC, assim como os diferentes atores inseridos neste programa.

\section{REFERÊNCIAS}

AZEVEDO, Sérgio de. Políticas públicas: discutindo modelos e alguns problemas de implementação. In: SANTOS JUNIOR, Orlando A. dos (et al). Políticas públicas e gestão local: programa interdisciplinar de capacitação de conselheiros municipais. Rio de Janeiro, FASE, 2003.

BALL, Stephen J. Profissionalismo, gerencialismo e performatividade. Caderno de Pesquisa vol.35, n..126, São Paulo, Sep./Dec. 2005.

BALL, Stephen J. Reformar escolas/reformar professores e os terrores da performatividade. Revista Portuguesa de Educação, Minho, v. 15, n. 2, p. 3-23, 2002.

BRASIL. Pacto nacional pela alfabetização na idade certa: formação de professores no pacto nacional pela alfabetização na idade certa / Ministério da Educação, Secretaria de Educação Básica, Diretoria de Apoio à Gestão Educacional. - Brasília: MEC, SEB, 2012. 
BRASIL. Pacto Nacional pela Alfabetização na Idade Certa: Apresentação / Ministério da Educação, Secretaria de Educação Básica, Diretoria de Apoio à Gestão Educacional.Brasília: MEC, SEB, 2014.

. Instituto Nacional de Estudos e Pesquisas Educacionais Anísio Teixeira - INEP. Indicador Nacional de Alfabetismo Funcional - INAF (2012). Disponível em: <http://www.inep.gov.br/nacional//INAF/resultados.html Acesso abril de 2018>.

Portaria $n^{\circ} 867$, de 4 de Julho de 2012. Institui o Pacto Nacional pela Alfabetização na Idade Certa e as ações do Pacto e define suas diretrizes gerais. Diário Oficial [da República Federativa do Brasil]. Brasília, n.129, p.22, 05 jul. 2012. Seção 1, pt. 1.

Lei n. ${ }^{\circ}$ 10.172, de 9 de janeiro de 2001. Aprova o Plano Nacional de Educação e dá outras providências. Diário Oficial da União, Brasília, 10.01.2001.

Parecer CNE/CEB n ${ }^{\circ}$ 04/08, de 20 de fevereiro de 2008. Orientação sobre os três anos iniciais do Ensino Fundamental de nove anos. Conselho Nacional de Educação. Câmara de Educação Básica, 2008.

Lei n. ${ }^{\circ} 13.005$, de 25 de junho de 2014. Aprova o Plano Nacional de Educação e dá outras providências. Diário Oficial da União - Seção 1 - Edição Extra - 26/6/2014.

BRASIL. Ministério da Educação. Planejando a Próxima Década Conhecendo as 20 Metas do Plano Nacional de Educação / Secretaria de Articulação com os Sistemas de Ensino (MEC/ SASE), 2014.

. Ministério da Educação. Conselho Nacional de Educação. Câmara de Educação Básica. Resolução No 7, de 14 de dezembro de 2010. Fixa Diretrizes Curriculares Nacionais para o Ensino Fundamental de 9 (nove) anos.

BRASIL. Ministério da Educação. Secretaria de Educação Básica. Diretoria de Apoio à Gestão Educacional. Pacto Nacional pela Alfabetização na Idade Certa. Documento orientador das ações de formação em 2014. Disponível em:

$<$ http://pacto.mec.gov.br/images/pdf/Formacao/documento_orientador_2014_versao_site.pdf >. Acesso em: abril de 2018.

Ministério da Educação - Manual do Pacto Nacional pela Alfabetização na Idade Certa. 2014. Disponível em: 〈http://pacto.mec.gov.br/images/pdf/pacto_livreto.pdf〉. Acessado em: maio de 2018.

CANDAU, Vera Maria Ferrão. Formação continuada de professores: tendências atuais. In: CANDAU, V. M. (Org.). Magistério: construção cotidiana. Petrópolis: Vozes, 1997, p.51-68.

CARVALHO, Gilcilene Teodoro; FRADE, Isabel. JORNAL LETRA A - O Jornal do Alfabetizador - Centro de Alfabetização, Leitura e Escrita Belo Horizonte, Faculdade de Educação/UFMG- ano 10 - n 37 - Edição Especial, março/abril de 2014.

CHIMENTÃO, Lilian Kemmer. O significado da formação continuada docente. CONPEF, UEL, 2009. 
ESQUINSANI, Rosimar Serena Siqueira. Performatividade e Educação: a política das avaliações em larga escola e a apropriação da mídia. Práxis Educativa, v. 5, n. 2, p. 131-137, jul. - Ponta Grossa, dez. 2010.

FERRARO, Alceu Ravanello. Alfabetização no Brasil: problema mal compreendido, problema mal resolvido. In: MORTATTI, M. R. L.; FRADE, I. C. A. S. (Org.).

Alfabetização e seus sentidos. O que sabemos, fazemos e queremos? Marília, São Paulo: Oficina Universitária, Editora UNESP, 2014, v. 1, p. 65-90.

FRADE, Isabel. O pacto no contexto das universidades. Jornal Letra A. Belo Horizonte, março/abril de 2014 - ano 10 - n 37 - Edição Especial. Entrevista concedida a Ana Carolina Marques Lage e Thaiane Bueno.

GROXKO, C. M. e PAIVA, L. P. Formação continua de professores dos anos iniciais do ensino fundamental. Disponível em:

<http://educere.bruc.com.br/arquivo/pdf2008/471_810.pdf>. Acesso em maio de 2018.

NÓVOA, Antônio. Os professores e a sua formação. Lisboa: Publicações Dom Quixote, 1992.

SANTOS, Sonia Regina Mendes dos. Descentralização, regime colaborativo e a formação em serviço de professores: um estudo sobre os desafios para a implementação. XVI ENDIPE Encontro Nacional de Didática e Práticas de Ensino - UNICAMP - Campinas - 2012.

SANTOS, Lucíola Licino de C. Formação de professores na cultura do desempenho. Revista Educação \& Sociedade, Campinas, v. 25, n. 89, p. 1145-1157, set./dez. 2004.

SAVIANI, Demerval. Sistema Nacional de Educação articulado ao Plano Nacional de Educação. Revista Brasileira de Educação, v. 15 nº 44. 2010.

SANTANA, Cristina, F. P. A. A política de formação continuada de professores e a sua relação com os tópicos da avaliação de desempenho - Prova Brasil / Cristina Fátima Pires Ávila Santana. - Dourados, MS: UFGD, 2011. $142 \mathrm{f}$.

SOUZA, Maria Goreti da Silva. A formação continuada e suas contribuições para a profissionalização de professores dos anos iniciais do ensino fundamental de Teresina PI: revelações a partir de histórias de vida. Dissertação apresentada ao Programa de PósGraduação em Educação da Universidade Federal do Piauí, 2008. Disponível em: $<$ http://www.ufpi.br/subsiteFiles/ppged/arquivos/files/dissertacao/2008/formacao_ensino

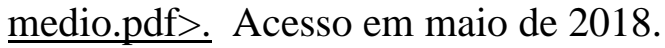

